\title{
Career Self-Management and Development of Multicultural Knowledge and Practice: Experience of Professional Counsellors
}

\author{
Priya S. Mani
}

\begin{abstract}
The focus of this research project explores counsellors' experiences and application of multicultural competencies when working with diverse clients. Using a descriptive qualitative case study approach (Yin, 2009), thirty professional counsellors engaged in semi-structured interviews. They reflected on various factors drawn upon in developing and incorporating a multicultural base of knowledge to inform their practice when working with diverse clients. This research study examines what it means to be a multicultural counsellor, including their perception of challenges and outcome expectations in developing a multicultural framework to situate their practice, and cultivation of professional resilience in their work with diverse clients. The article concludes with a discussion for future work in the area and presents a broadened scope of counsellor career adaptive behaviors implemented in effectively working with diverse clients.
\end{abstract}

Keywords: counsellors' experiences, multicultural competency, career adaptive behavior of counsellors, qualitative research, and professional resilience

\footnotetext{
Dr. Priya S. Mani, is an Associate Professor in Counselling Psychology in the Faculty of Education at the University of Manitoba. Her research interests include aspects pertaining to career development, diversity, and exploration of the professional development of counsellors. This article is based on portions of a paper presented at the 8th World Congress of Psychotherapy Conference, Paris, France (July, 2017). Recent publications include: Shepard, B. C. \& Mani, P.S. (Eds.). (2014). Career development practice in Canada: Perspectives, principles, and professionalism. Toronto, Ontario: Canadian and Education Research Institute for Counselling (CERIC); Shepard, B. C. \& Mani, P.S. (2014). Career development for students: Elementary to high school. In B.C. Shepard \& P.S. Mani (Eds.), Career Development Practice in Canada: Perspectives, principles, and professionalism (pp. 333-360). Toronto, Ontario: Canadian and Education Research Institute for Counselling; and Mani, P.S. (2011). South Asian Canadian Young Men and Women's Interest Development in Science: Perception of Contextual Factors. Canadian Journal of Family and Youth, 3 (1), 41-78. doi: https://doi.org/10.29173/cjfy12171
} 


\section{Introduction}

Due to changing demographics and diversification of the population, the role of the counsellor has expanded. Within a Canadian context, it is important to consider aspects pertaining to multicultural counselling competencies (MCC) in light of living in a pluralistic society and how that shapes conceptualizations of MCC. There is limited research of the application of MCC by professional counsellors (Abreu, Chung, \& Atkinson, 2000; Arredondo \& Toporek, 2004; Arthur \& Collins, 2015a; Hill, 2003). This study focused on outlining what factors contribute to the development and incorporation of MCC into practice for professional counsellors. The research has been limited to broad and overly general principles pertaining to the attitudes, beliefs, and skills that counsellors need to promote MCC (APA, 2017; Pederson, 2001; Sue, 2001; Sue \& Sue, 2013). To date, a lack of agreement exists regarding how to prepare counsellors for working with diverse clients (Arthur, 2018; Knapik \& Miloti, 2006; Manese, Wu, \& Nepomuceno, 2001).

\section{Conceptualization of Multicultural Competencies}

To help define multicultural competencies, various counselling educational programs have adopted the conceptual Multicultural Counselling Model (MCC) developed by Sue et al. (1998; 2001) that incorporated the tripartite model that emphasized personal awareness/beliefs, skills, and knowledge (Knapik \& Miloti, 2006). However, portrayal of competencies (knowledge, awareness, and skills) as separate entities does not fully capture how dimensions interact into representing a whole construct. Sue's model (2001) placed a strong emphasis on the consideration of cultural norms when developing relationships and not enough on highlighting the importance of developing specific skills to form strong relationships with diverse clients (Collins \& Arthur, 2010; Kottle \& Balkin, 2016). Universal features of healing (including the client's expectations, the strength of relationships, and importance in faith in the process of engagement) are important considerations when working with diverse clients that is not explicit within the tripartite model (Duncan, Kirkendall, \& Citro, 2014; Frank, 1972; Knox, 2013; Norcross \& Wampold, 2011; Wiggins, Elliott, \& Cooper, 2012). Consequently, it becomes difficult to create practical guidelines to implement the model to inform one's professional work (Ridley, Baker, \& Hill, 2001). As a result, new MCC frameworks have emerged that build on the essential aspects of the tripartite model, incorporate an emphasis on the strength of the relationship, and integrate universal therapeutic aspects of healing to reflect a shift in understanding of culture and diversity as it shapes practice (Collins, 2010; Collins \& Arthur, 2010).

Sue (2001) differentiated between multiculturalism (racial and ethnic differences) and diversity (individual differences such as age, gender, sexual orientation, socioeconomic status, ability/disability, religion and other characteristics by which people may self-define). The concern was that no guidelines were provided as to how counsellors resolve dialectical tensions in considering both the narrowly defined aspects of cultural groups based on cultural norm research as well as broad and inclusive aspects of cultural identity (including various aspects of diversity) in practice for counsellors. Understanding the importance of how counsellors' definitions of culture and diversity shape client and counsellor interactions is a key variable in the practice of 
one's work (Arthur \& Collins, 2009; Peters, 2017). Scholars in the field of multicultural discourse remain divided over whether emphasis be placed on cultural norm research (Helms \& Richardson, 1997; Sue, 2001) or more inclusive aspects of cultural identity when counsellors engage in case conceptualization with clients (Casas, Park, \& Cho, 2010; Chopra, 2013; Hill, 2003; Lee, 2013). The orientation of the counsellor will most likely determine which aspect of cultural competency (the stance of multiculturalism or diversity) will define and shape practice.

\section{Career Self-Management and Self-Efficacy of Counsellors}

The Social Cognitive Career Theory (SCCT) outlines how career relevant choices are enacted and performance outcomes achieved (Lent, 2013). It is equally important to consider how SCCT could be a useful theoretical framework for understanding the counsellor's development of certain competencies and professional helping skills over time as they inform and shape practice (Patton \& McMahon, 2014). The complementary model of career self-management (Brown \& Lent, 2017; Lent, Ezeofor, Morrison, Penn, \& Ireland, 2016; Lent, 2013) focuses on understanding micro-level processes such as development of competencies in one's field, self-regulation, coping skills, and adaptive performance, which was a focus for this study. The complementary career selfmanagement model also has an explicit focus on exploring personal agency and adaptation to challenges within a social context for development of competencies. In relation to understanding personal agency in connection to the development of counselling practice, two additional areas have also emerged deserving of attention that ground this study: multicultural counselling selfefficacy and social justice self-efficacy of counsellors.

Multicultural counselling competence (MCC) requires counsellors to believe in their ability to work with clients from diverse backgrounds. Counsellor self-efficacy (CSE), involves counsellors' beliefs about their capability to perform specific counselling related behaviors. Counsellors' who have a high degree of self-efficacy tend to be more resilient and reflect stronger commitment and perseverance to work through difficulties encountered with diverse clients (Bandura 1986; Jones, Kawena, Nakagawa, Cevasco, \& Sit, 2016). In light of considering the needs of professional counsellors, the need to increase multicultural counselling self-efficacy (MCSE), involving a counsellor's belief in her/his ability to successfully counsel someone from a different cultural and diverse background than their own, becomes imperative (Barden \& Greene, 2015).

Engaging in social justice efforts to help improve client well-being is an important component of one's work (Speight \& Vera, 2008; Vera \& Speight, 2003). Social justice advocacy has emerged as a competency in the field; two issues affect social justice self-efficacy beliefs of counsellors. The first issue pivots on the extent and means by which counsellors emphasize change and how to facilitate more equal opportunity for clients (by addressing structural inequalities within organizations or focussing on social inequalities) (Palmer \& Parish, 2008). The second issue revolves around the understanding and defining the term multiculturalism as it informs practice (Palmer \& Parish, 2008). Focusing primarily on the inclusion of values does not address how counsellors integrate social justice principles in their work with clients, and acquire skills to address structural inequalities to help improve well being of clients (Arthur \& Collins, 2014; 
Collins, Arthur, Brown, Kennedy, \& Roberts, 2015). Social justice and multicultural competencies require grappling with what multiculturalism and social justice actually means for their professional identity and uncertainty about how to incorporate understandings into their professional roles and practices (Neville, 2015; Ratts \& Pedersen, 2014). Understanding what contributes to counsellor development of multicultural competencies (including advocacy skills) would help address an important emerging gap that could help aide novice counsellors (Miller, Sendrowitz, \& Mallinckrodt, 2011; Ratts, Singh, Nasser-McMillan, Butler, \& McCullough, 2016; Swartz, Limberg, \& Gold, 2018).

\section{Rationale}

This study looked at factors that professional counsellors consider in developing a multicultural framework to inform their practice and influence on personal agency appraisals over time. The research questions formulated for this study were: (a) what factors do counsellors consider in developing multicultural competencies; (b) what types of challenges do counsellors experience during the development of multicultural competencies and how are they resolved; and (c) what are the outcome expectations that these counsellors have when working with diverse clients.

\section{Methodology}

\section{Qualitative Method Selected: Descriptive Case Study Approach}

Within this qualitative descriptive case study (Yin, 2009), an examination of the counsellor's development of multicultural competencies among professional counsellors was explored. The researcher began with a theory in the literature, initially drawing from a deductive process followed by an inductive process, in an effort to describe a phenomenon (Hsieh \& Shannon, 2005). Criteria for selecting participants were: (1) completion of a graduate degree in counselling or related field of psychology; (2) a minimum of five years of work experience as a counsellor in Canada; and (3) being employed in community mental health agencies working with diverse children and families. Upon receipt of ethics approval from an institutional review board, electronic invitations were sent to various agencies to recruit participants. Thirty professional counsellors, who work with culturally diverse clients, provided informed consent, and voluntarily took part. Eight participants were working professionally in the west coast of Canada and twentytwo participants were working in the prairie provinces comprised of central Canada. Nine participants were visible minorities (out of which five participants were immigrants to Canada as well as four participants were children of immigrants). Fifteen participants had concealable aspects of cultural/diverse identity. The remaining six participants identified as having concealable and perceived stigmatized aspects of cultural/diverse identity. In-person interviews and recruitment of participants concluded based on a sense of data saturation reached (Aldiabat \& Navenec, 2018). Data saturation consisted of code saturation (outlining main domains of inquiry) combined with meaning saturation (capturing the complexities of patterns within the main domains) (Hennink, Kaiser, \& Marconi, 2017). 


\section{Phases of Data Collection}

The five-phase process consisted of: (1) Before the first interview, participants received the semi-structured interview questions and were asked to construct a mind map on the important influences on their current and anticipated counselling practice while working with diverse clients. A mind map encourages participants to start with a nucleus idea (placed in the centre of the page) and any further ideas generated would stem outward from the nucleus in any direction (Wheeldon $\&$ Faubert, 2009). (2) Participants engaged in one interview, of one- hour duration, in which the researcher followed an interview guide of targeted open-ended questions. Questions asked revolved around: (a) interest development working with diverse clients, (b) perception of supports and barriers in developing and implementing a multicultural framework, (c) factors considered to enhance professional resilience when working with diverse clients, (d) challenges anticipated when working with diverse clients, (e) strategies drawn from to manage challenges, and (f) future career plans to enhance multicultural competency. (3) Transcription of interviews combined with a cross comparison with case study notes created after each interview, served as an audit trail. (4) Participants received interview transcripts to check for veracity and portrayal of information. (5) The primary researcher double coded each interview with a 14-20-day interval to ensure consistency of results (Schreier, 2014).

\section{Qualitative Content Analysis}

Qualitative content analysis uses a combination of inductive and deductive approaches that have different dominancy at different phases of analysis (Sandelowski, 2000). The deductive dominant phase used at the beginning of data analysis applied to the structuring of main categories for the data and engaging in a data reduction process by: (1) Code each transcript line-by-line as well as placing information into concept-driven main categories according to the predefined concepts of career self-management model (Lent, 2013). (2) Create a table that would consist of all the interview statements that reflect the concept-driven main categories for each participant. This resulted in five main categories: a) contextual affordance and socialization, b) Learning experiences, c) structure of opportunity, d) outcome expectations, and e) choice goals and action.

The inductive dominant phase consisted of four phases that focused on creating a categorization matrix (Table 1) and representing results. The categorization matrix required: (1) Re-grouping statements within each of the five main categories into specific domains. (2) Linking the underlying meanings of domains found within a main category and determining an overarching theme (Polit \& Hungler, 1999; Graneheim \& Lundman, 2004). (3) Noting representativeness and number of participants representing the patterns of responses in the categorization matrix. The very last stage of data analysis: (4) Systematic revision and expansion of the categorization matrix required a review and cross comparison of transcripts and case notes to check for consistency of patterns of statements into groupings (domains), and overarching themes (meanings). 


\section{Validity, Reliability, and Trustworthiness of Data}

Yin ${ }^{e e}$ (2009) three criteria to establish validity of the data were: (1) Internal validity consisted of triangulation of data, creating a selective sample, and establishing veracity checks of interview statements with participants. (2) Reliability involved consistent data analysis procedures, comparison of case notes, and establishing double coding per participant interview. (3) External validity was through analytical generalization of results of to theory (Yin, 2009). Trustworthiness of the data, represented through the categorization matrix (Table 1), illustrates the five main categories that incorporates the overarching theme and corresponding domains. The frequency in which each domain occurred by participant and representativeness of the domain across participants is noted. For documenting representativeness of a domain, it was decided that if a domain was noted by 6-9 participants it was called Occasional, 10-19 participants was Frequent, and 20-30 participants was termed General. Domains noted by fewer than 6 participants were not included.

\section{Results and Discussion}

This section explores the key research questions that informed the project, the corresponding overarching themes that emerged, and integration of widely representative quotations of the sample of participants from transcripts highlighting the essence of each overarching theme. The results and discussion combines and offers examples of how the occasional, frequent, and general reported domains found within the five main categories contributed to understanding the emergence of the overarching themes. The researcher's aim was specifically to explore, identify, and describe relevant career adaptive behaviors engaged by counsellors when working with diverse clients. As such, this section elaborates on the over arching themes and overall patterns that emerged and are reported under each research question.

\section{Research Question \#1. Factors that contribute to interest development working with diverse clients}

The main category, contextual affordance and socialization experiences, explored what contributed to interest development of counsellors working with diverse clients. Contextual affordance consists of the participant's indirect perception of social forces and influence over development of interests (Lent, Brown, \& Hackett, 2000). The overarching theme for this category was developing a gradual paradigm shift in their worldview orientation towards understanding diversity over time (Table 1).

Participants generally discussed how important it was to understand the multiple strands of diversity in their own life. This process entailed what participants described as "unpacking the taken for granted assumptions" of their personal worldview. Many described this process as trying to understand the "blueprint of their socialization experiences" which was difficult. A participant described it as equivalent to "trying to make sense of the air we breathe....you can't see the air, 
you can only feel it.....and you need to be mindful to notice the air we breathe which is hard work". Engaging in an ongoing internal dialogue regarding multiculturalism consisted of participants need to deconstruct the term for themselves and search for their own personal definition of culture incorporating unique diverse threads (gender, class, culture, age, disability, structure of the family, sexuality) which shaped their self-understanding and subsequent work with clients. Self-reflection of lived experience of difference over time helped counsellors grow. By identifying new strands of diversity that affected their self-understanding, they could encompass new worldviews and increase their range and perspective of ones own. The participants also commented on the importance of "revisiting definitions of diversity over time" and recognized that personal definitions shifted based on further understanding of the background of the historical context of their own lives (including a heightened socio-political awareness on a national and global level) that impacted personal narrative. Since "change was gradual" they felt the need to "revisit, question, and engage in further inquiry" at different time points of personal development. Additionally, participants discussed how bearing witness to others hardships from an early age and having exposure to role models in the family who engaged in social activism contributed to their interest development in meeting the needs of marginalized and underserved populations and shaped initial personal advocacy style.

Frequently, participants would discuss the emotional component of person-place bonds in defining worldview. They discussed how their experiences in living in urban and/or rural environments, and/or living and working abroad contributed to internalizing values and meanings that informed their work with clients. They would actively revisit these unique spatial contexts of lived experience and reconstruct their cultural and historical meanings. Additionally, for counsellors who identified religious/spiritual beliefs they discussed what aspects of their belief system came into play with clients and what aspects remained as background with heightened consciousness over time. Participants experienced a "redefinition of self" based on unique personal struggles encountered that resulted in a shift in their worldview orientation, which sensitized them to understanding the underlying process that clients contended with and increased empathy.

The overall pattern for this category was that participants viewed diversity as multiple and complex. They recognized that cultural differences may include multiple variants (e.g., gender, sexual orientation, socioeconomic status, age, educational level, language, and religion) and what emerges as significant to self-understanding will shift over time and inform practice. The counsellor's willingness to practice what one described as "suspending judgment and determining value orientations that informs practice", parallels how they learn to respect and come to understand the process their clients' also engage in when sharing deeply ingrained aspects of self. This process contributes to developing cultural empathy/humility and helps advance the counselling relationship and the foundation for implementation of a multicultural orientation that involves an open mindset and a lifelong commitment to self-examination (Hook, Davis, Owen, \& DeBlaere, 2017; Mosher et al., 2017).

\section{Research Question \#2. Key Learning experiences in developing and implementing a multicultural framework}

The main category, perception of key learning experiences, addressed what contributed to developing and implementing a multicultural framework when working with diverse clients. The 
main overarching theme was developing contextual consciousness when working with diverse clients (Table 1). Learning experiences (based in both informal and formal contexts) to inform practice help to organize future course of actions and whether individuals persist in the face of challenges and subsequent changes encountered in the field. Understanding the perception of the social context of learning in which career adaptive behaviors and self-set goals arise contributes to understanding the emergence of personal agency in determination of career development (Lent, 2016).

The key learning experiences drawn upon to inform the development of making context sensitive judgements in one's work seemed to originate in both formal (educational and workplace settings) and informal contexts of development (development of personal imagination and curiosity to inform practice). Occasionally, participants communicated that they experienced a heightened critical consciousness and paradigmatic shifts in their learning experiences through graduate practicums that had a specific supervision focus on diversity and multiculturalism. Supervision received in niche diverse practicums served as "building blocks for reflective practice" in their current work with clients. Over time, and through the modeling of their practicum site supervisor, they developed an internalized framework in which they could engage in reflective questioning involving challenging perspectives. Participants communicated that they started to "deepen their understanding of what was personal, political, and professional and would muddle through developing a personal advocacy style" with clients while considering the influence of macro concerns (social, economic, and political) on the client's issues. Discussion reflected the struggle, commitment, and work necessary to create "a new intentional lens" to view their work with clients.

The contextual barriers they frequently experienced in graduate school that restricted their learning were a limited number of faculty as well as students within their cohort. Participants stated a "desire to hear more stories of difference" amongst their fellow peers and instructors as an aspect that would have helped develop "context sensitive judgements". As they became more invested in their work they would intentionally and incrementally seek out variant experiences to challenge themselves in a systematic process of personal discovery and self-growth (volunteer work in their community, serving as a board member for issues pertaining to diversity, volunteering for NGO overseas, gap year, travel, and working abroad). Subsequently, they engaged in new diverse contexts of meaning and emotion for self-growth and increased their risk tolerance in their professional and personal lives.

The counsellor's ability to draw from their imagination is a significant component of integrative complexity (Clark, 2010; Day-Vines, Booker, Steen, \& Arnold, 2018; May, 2015; Trimble, 2010). They balanced this by consulting with key sources from the ethnic/diverse community about cultural practices, reading books, listening to world music, and engaging in reading literature and watching movies or documentaries for more experiences. In particular, participants frequently sought out various opportunities to travel, live abroad in a different culture, or had grown up with exposure to different cultures reflected a comfort level and capacity to acknowledge and integrate competing perspectives and feel more comfortable with creating creative and hopeful interventions for diverse clients. Participants offered preliminary thoughts about the importance of counsellor's imagination of self in relation to their clients that contributed 
to integrative complexity. A participant stated, "Imagination was essential and helped move between positions of connection (which allowed increased capacity for feeling) and curiosity (which increased ability to develop creative interventions) with clients".

They frequently sated that part of creative engagement incorporated the application of interdisciplinary approaches of helping into real world contexts. These particular participants had undergraduate degrees in various disciplines and had completed graduate studies in counselling as a mid career change. Those who had a degree in different disciplines (business, social work, environmental sciences, sociology, philosophy, theology, fine arts, or architecture) viewed learning as a multidimensional process that incorporated different frameworks with "understanding the client as well as themselves from multiple vantage points". They saw value in having varied work and educational experience in different fields and as a participant stated, "there seems to be a lot of different pathways to improve the well being of clients by not only focussing on a psychological perspective". Combining knowledge from different disciplines to inform ones work seemed to provide a platform to perceive creative openings with clients found in drawing from different disciplines. They perceived "interdisciplinary knowledge as a quality that strengthened their imagination" and generated more creative ideas of how to approach and engage in the therapeutic alliance with clients. They discussed this as an aspect that required further refinement and through intentional practice and engagement over time would help to broaden their imagination.

Another important informal context identified generally by participants involved identifying "catalysts for professional growth" that occurred in informal contexts of their lives. Participants discussed how influence of personal life events and stages had an impact on professional growth, influence of life course trajectories, recognition of life stages not confronted yet that would impact their work with clients, and subsequent impact on the use and development of imagination. They also discussed how over time the embracement of various life roles in their own personal trajectory heightened their consciousness of the importance of the meaning-making process behind making choices and what it meant to be an "active agent in shaping their life". This in turn enabled them to have a better understanding of their clients when faced with various "crossroads" in their lives and the heightened understanding of the role of privilege and impact on life choices. Clarification of their worldview and defining moments in their lives, led them to consider how they managed dialectical tensions in their own lives and sensitized them to stories shared by others. Developing a contextual consciousness is a learning process that involves agency and intentionality (Koster, 2017; Trede \& McEwen, 2012). As counsellors matured and confronted different experiences in adulthood, their professional identity changed over time and contributed to the capacity for context sensitive judgements during practical involvement in ones work (Trede $\&$ McEwen, 2012). Participants generally discussed how they learned to use culture and diversity in an appropriate way with their clients. They discussed the dilemma of not knowing when culture or what aspects of diversity was related to the presenting issue. Overtime, counsellors developed a strategy of asking clients what cultural characteristics may contribute to personality, worldview, and integrated these perspectives to address client needs. 


\section{Research Question \#3. Perception of structure of opportunity and identification of contextual supports and barriers in the workplace}

A focus on counsellors' perception of structure of opportunity in the workplace helps understand the interplay between personal agency and opportunities sought out at work. As a component of professional identity development, the central overarching theme was types of learning spaces created by counsellors for developing the competency of working with diverse clients in the workplace with the purpose to increase emotional learning and opportunities for self-growth (Table 1).

Understanding and enhancing future infrastructure in the workplace (mainly related to receiving multicultural supervision) facilitated professional resilience. Participants generally reported that community-based agencies encouraged counsellors to seek supervision or consult with colleagues who had a greater knowledge and multicultural expertise in a particular area. They also identified role models/mentors in various communities in which they worked (outside of the agency), such as religious leaders, political representatives, as well as indigenous community identified elders/healers to help understand client issues and how to become an advocate for creating healthy communities. For counsellors employed in agencies that had regular built-in supervision and additional training opportunities available contributed to professional resilience. From the perspective of these counsellors' resilience was maintained based on supervision being accessible and part of their support network. They thought that finding a coordinated response to difficult clients to be easier as "norms around dealing with difficulties with clients are built-in to facilitate problem solving at work". These participants valued being able to consult-in house as they were working in collaborative teams in their workplace. Another interesting finding was that the majority of paid counsellors engaged in unpaid volunteer work in specialist areas of diversity through different local agencies. Through volunteering, they felt that they would have access to working with a new clientele and increase personal exposure with diverse groups. Volunteer unpaid work included serving on boards with a focus on diversity, volunteering abroad for an NGO, and local community agency work. They perceived that engagement in volunteer work was an embodiment of their personal values and that it contributed, as a participant stated, "to establishing real world relevancy for developing effective and inclusive counselling practice" that could translate into their workplace. It also represented an opportunity to receive free training/supervision and to keep abreast of developments in the field. In turn, it also offered counsellors another bridge to organizational networks to draw from to address consultation and increase resilience.

For counsellors that did not have in-house supervision, when confronted with thinking of client cases they required greater self-sufficiency with meeting their needs outside of the agency and felt more vulnerable. In some instances, they would seek out additional paid work in other agencies to establish stronger ties to the professional community to gain the social support and expertise needed when working with diverse groups. The challenges included finding it difficult to manage the cost and time required for supervision.

Counsellors stated that directors/managers in their workplace seemed to recognize the desire of counsellors to engage in more intentional infusion of creative approaches to service delivery. Counsellors generally communicated that managers who allowed them to "shift the 
therapeutic frame" and experiment with new modes of delivery of services and was important as they made more forays into creative approaches to reaching and maintaining relationships with diverse clients. Counsellors discussed engaging in more home visits, delivering workshops directly in diverse communities, offering wilderness and Eco therapy, encouraging clients to form sustaining self-support groups in the community, and providing workshops within the workplace for staff to increase exposure to diverse issues. As the majority of these counsellors also worked across and beyond their own organization to inform their practice, they would slowly gain recognition for their work through colleagues (inside and outside) the primary agency of employment. They started to create counselling interventions for clients that provided "creative educational openings to make meaning in context" and help clients engage in experiential learning and to become integrated within community.

Participants occasionally stated that they would create services for a niche area of diversity underserved in mainstream services through private practice and that indication of success would be when other people in the field would consult them for their expertise. These counsellors became more innovative with the use of personal and community resources to advocate for marginalized groups of clients, which represented "a new learning edge in their professional development". They became more comfortable with building common ground with different constituencies to help meet the needs of their clients. They used their knowledge/leverage with the different systems in the community to help "walk alongside and be there for their client" to manage societal and system barriers/challenges in unique ways.

The challenge counsellors generally reported was sustaining learning and maintaining communities of practice in the workplace. Finding time to invest into advocacy efforts, creation of new interventions, time for supervision, time needed for trust building with clients, and lack of mentors within organizations to draw from with an expertise in diversity issues were challenges to sustaining practice. Counsellors also described the process of learning from mistakes with clients and "breaking a cycle of regret" as challenging. The cycle consisted of rumination on past mistakes, followed by subsequent feelings of regret, and trying to break the cycle by also focusing on new and past client successful interactions. This ability to fluctuate was vital to the processing of their experiences (Shepherd, Patzelt, \& Wolfe, 2011). Additionally, counsellors noted that norms in the workplace that were "failure tolerant" emphasized analysis of failed attempts which helped them overcome their fear of failure, difficult emotions attached to event, and still consider taking risks with doing things differently when working with future clients. Individuals believed they could improve their ability to learn from failure if they also managed to have strong counter balancing forces in their experiences to draw from to keep them grounded while confronting difficult emotions (Shepherd, Patzelt, \& Wolfe, 2011). Counsellors communicated that "learning from failure was an intentional process of self-reflection and helped to sustain hope in their work" and felt that they could benefit from further tools to help in the process of their emotions to increase their ability to learn from failure and not shut down in their work with clients.

\section{Research Question \#4. Identification of choice goals and actions that contribute to professional resilience when working with diverse clients}

The main category, perception of choice goals and actions, addresses adaptive career 
behavior (Lent, 2013). The primary focus is how individuals use coping skills to foster professional resilience and career development needs (Lent, 2013; 2013a). The main overarching theme was creative practitioner inquiry to build professional resilience and positive adaptation to life challenges (Table 1).

An important choice goal and action that contributed to professional resilience was the importance of revisiting and revising their theoretical framework that underpinned their work with clients. Counsellors would try to make sense of their discipline in light of their own personal lived experiences. Generally, many counsellors stated that "the personal was professional" and interventions created for clients took into consideration their experiences with actual work with clients in combination with considering their own personal lives as a necessary component of understanding their work with clients. This highlights the importance of building one's unique theory derived from our own identity and experiences (Drapela, 1990; Kramer, 2000). Counsellor's personal lived experiences foreshadowed their orientation to counselling practice with diverse clients that shifted, broadened, and deepened over time (Wong-Wylie, 2006). Personal reflection would primarily focus on their own lived experiences of managing and confronting challenges in their own life and embodiment of personal values pertaining to diversity; they came in touch with their preferred theories and interventions that informed their work with diverse clients. They also clarified their core values that grounded them in their personal and professional spheres of life. These core values were commonly described, "as anchors in their professional work with clients and embodied their work". The personal stories that they lived by (that also informed their working alliance with clients) shifted and changed based on subsequent learning from facing personal transitions and life/work challenges.

Counsellors generally stated they would challenge the cultural norm research and shifted to more context dependent knowledge of understanding culture along the spectrum of diversity. By revisiting their own self-definition of diversity, they recognized that it changed over time. Perception of the historical context and socio-political awareness of diversity in society (national and global level) influenced their personal narrative. In turn, counsellors "noticed that they were listening to strands of diversity in clients' lives differently" taking into account contextual factors and within group differences that influenced identity construction. Counsellors recognized that the clients' self-definition of culture, like their own, would also shift and change based on context and life stage. The importance of revising and revisiting their theoretical stance helped counsellors strengthen their professional resilience when working with diverse clients.

Participants generally communicated that creating hopeful interventions represented an important choice goal. Counsellors' described hopeful interventions by highlighting strengths, establishing future focus, recognizing possibilities, and using meaningful metaphors understood by the client. Counsellors communicated that a central challenge was how to "infuse hope from clients' own language and the creativity needed to provide new understandings while still honoring the worldview of the client". However, when hope based interventions were successful they could see how clients' were more inclined to make positive adaptations to life challenges. In turn, they increased their own which reflected an important component of professional resilience. 


\section{Research Question \#5. Consideration of future challenges and career plans to enhance multicultural competency and practice}

The main category, outcome expectations, was used to understand professional counsellors' perception of future expectations of their efforts working with diverse clients. The importance of cultivating a resilient future and professional identity was the overarching theme that emerged for counsellors (Table 1)

Diversity activism for counsellors generally involved outreach activities to strengthen multicultural sensitivity and commitment to advocacy with clients. They increased engagement in resource activation to advocate for marginalized groups. Finding innovative approaches to address service gaps and confront blind spots in agencies and the wider community was another outcome expectation. They became involved in service volunteer commitments (serving on various boards) and taking on more leadership roles in shaping policy and promotion of diversity through community outreach. Additionally, there was a growing focus on community capacity building within their workplace and they would provide in-service opportunities to colleagues, challenging and confronting colleagues when necessary. Some would also share composite stories of clients with the public to raise awareness and create change in societal attitudes. Additionally, counsellors engaged in active reflection of defining their personal advocacy style while working with clients. They described the process of working on their personal advocacy style as one of "building personal courage over time to practice active engagement of their values and operating outside of their comfort level". In relation to direct work with clients, the majority of participants would engage in pro bono work and defined it as a reflection of their fundamental value and commitment to advocacy work. They also hoped that their advocacy style would indirectly model to clients' resourcefulness, taking initiative, warmth and acceptance through "embodied actions". Generally, counsellors communicated that advocacy efforts "did not come naturally and there was no official training in social justice in connection with direct work with clients through their university programs". Counsellors experienced discouragement in their work as they struggled to find ways to "break the cycle and bring research to inform practice". They communicated the importance of maintaining morale while engaging in advocacy and found that consulting with colleagues or finding a mentor on diversity in their field was essential. Occasionally, participants also communicated interest in pursuing further graduate work in counselling psychology with the intent to engage in research to broaden their horizons of how to integrate counselling and advocacy within their work.

In relation to social justice and development of advocacy and counselling skills, generally participants communicated their learning was developmental. They uniformly expressed comfort with engaging in micro interventions (addressing intrapersonal or focusing on the integration of significant family members and/or friends). Participants discussed how they would require further training in advocacy and support from their workplace to engage in institutional and communitybased interventions that would address systemic issues. In the area of macro level interventions requiring advocacy efforts and tapping into changing the local, provincial, and federal policies and laws that affect clients they felt that this would be a "learning curve and a level that they had not been adequately prepared for prior to entering the workforce". Additionally, international/global interventions, which involve addressing world affairs that obstruct the well-being of clients, were 
beyond their training and expertise. In all instances, counsellors understood that working with clients required a shift in the therapeutic frame of practice and needed to extend as a participant stated, "beyond the traditional office walls". On an as needed basis, counsellors would seek to connect with various counselling and non-counselling agencies to expand their understanding of effective counselling interventions, as well as to enhance understanding of how power, privilege, and oppression may intersect in work with clients. Counsellors would also initiate learning from nontraditional forms of helping (like legal services) that connected to their client populations and how developing trusting relationships with key stakeholders within the community developed over time.

Building a toleration of difficult emotions in ones work with clients became an important feature of how the majority of counsellors would sustain learning even when feeling "stuck" in their work. Participants learned how to become more patient when contending with client setbacks and more self- compassionate learning from mistakes. A participant described the learning experience from failed encounters with clients as "visiting the hard places and experiencing hurtful awakenings". Many participants also applied principles of mindfulness to stay grounded when thinking of stressful client cases. Sensitized to the fragility of clients' lives, they reframed setbacks with clients as a "puzzle", and maintained "a stance of curiosity", and enthusiasm of others. They would "experiment by ruling things out" and became more comfortable with making decisions despite incomplete information (concealment strands of diversity). Additionally, counsellors adopting more self-compassion for mistakes in their work became a crucial component that contributed to sustaining interest and helped participants persist in continuing to work and "pick up and try again".

Future outcome expectations, uncertainties, and identified learning edges to enhance ones work were critical aspects to understanding the future challenges in creating a resilient future and professional identity for themselves. Generally, participants communicated their concern with learning how to cope in relation to unresolved issues that emerge in counselling clients. They would have appreciated professional development on advanced mindfulness training to stay grounded while they navigated dealing with the "unknowns" of clients' lives and still learning to "stay open to experience". They desired further opportunities to learn how they could address historical wrongs with marginalized groups and "bridge divides" with clients. Counsellors communicated that they felt that they were on a "learning journey" with their clients and that they co-actualized in the process of engagement with their clients. As an aspect of sustaining resiliency in their work, the desire to discuss this process of co-actualization in supervision was an aspect that they wished viewed as a strength. Another future outcome expectation generally expressed by participants was their wish for increase in their advocacy skill through the development of crosssystem collaboration between various community agencies. To address this need, counsellors expressed that a 9-month work transfer every five to eight years to experience different service delivery models might help. Participants generally communicated that another new learning edge would be to assume a leadership position (management) in a niche area of diversity to learn and help shape policy development. 


\section{Implications for Practice and Future Directions}

The overarching themes of the study has potential for helping to advance the research field by providing preliminary ideas from which novice counsellors may be able to draw from in order to increase their own understanding of how to create connections and fill in gaps between multicultural knowledge and practice. Results indicate that a counsellor's personal worldview will shape their orientation towards the concept of diversity. The majority of counsellors' view that an emphasis on an inclusive view of multiculturalism that incorporates the client's intersection of multiple social identities (for example, gender, socioeconomic status, age, and disability) should have equal weight in conceptualization of culture. Over time, counsellors who adopted this point of view suggested that their need for culture-specific theories to inform their practice decreased (Collins \& Arthur, 2010; Weinrach \& Thomas, 2004). Results point to the importance of unpacking how counsellors integrate understandings of culture and diversity to address client wellbeing. Results also indicate that counsellors could benefit from additional personal tools to learn how to become resilient problem-solvers, become better at tolerating ambiguity, and in turn increase their own sense of self-efficacy in their work. Researchers have pointed to the need for counsellors to be more prepared for the emotional challenges they will encounter in their work with diverse clients (Arthur \& Collins, 2014; Collins, Arthur, \& Wong-Wylie, 2010). With more personal tools available to enhance counsellor's ability to stay open to their own learning process, practicing counsellors can be encouraged to proactively address their own developmental trajectory and engage in various experiences designed to enhance their creativity, cognitive complexity, and coping strategies.

An important consideration to take into account is how different stakeholders and social agencies in society change over time and impact it has on counsellor's professional resilience and engagement in creative outreach with diverse clients. In this study, a pivotal turning point for counsellors was exploring the role that volunteering served to complement paid work in their field as a creative adaptive response to addressing their needs for supervision, consultation, and learning best practices within a changing social world. Additionally, as counsellors develop over time, different life roles may become salient and questions regarding what contributes to people's preferences for pursuing particular roles (paid work, non-monetary work, private practice, and balancing of different personal life roles) becomes important to revisit for future research (Sterner, 2012; Super, 1990). Another important consideration is how to enhance future infrastructure and norms in the workplace to facilitate professional resilience for counsellors. In this study, what became apparent was that counsellors would revise their theoretical framework over time. In turn, they would also modify their professional goals and would incrementally seek out situations of discrepancy to increase their risk tolerance with working creatively with diverse clients as a component of career self-management. Lent (2016) believed that the choices made in the workplace is a dynamic enterprise and helps to sustain interest development in one's career. Results of this study indicate that appraisal of opportunity structures (supports, barriers, and opportunities) found within the workplace and various social systems drawn from to inform one's practice contributes to strengthening career choice goals and decisions made by counsellors to sustain practice. 
This study provides a glimpse into counsellors understanding of helping skills acquired, processes, and outcomes of how multicultural competencies are developed and applied. Additionally, hope-based interventions emerged as a form for maintaining positive momentum in their work with clients. Further exploration of what contributes to restoring hope (life-career dreams), agency and meaning in their lives might be a next step. The results suggest that the process of creating a personal working definition of multiculturalism when working with clients to inform practice is a consciously active, negotiated, and multifaceted process. Future research could explore decisional coping efficacy of counsellors when faced with taking empathic risks to bridge divides as well as engaging in self-reflection of failed experiences with clients. Due to the limited sample size, some potential limitations exist. The participants also had strong levels of self-efficacy in their work and it is unknown if similar experiences are held by individuals whose self-efficacy appraisals may vary in their work with diverse clients. Notwithstanding these limitations, the present research represents a useful step toward enriching an emerging research area about multicultural competency and the challenges encountered when working with diverse clients.

Table 1

\section{Summary of Inductively Developed Categorization Matrix}

\begin{tabular}{|c|c|c|c|}
\hline \multicolumn{4}{|c|}{ Category: Contextual Affordance and Socialization Experiences } \\
\hline Domain & Representativeness & Number of cases & Overarching Theme \\
\hline $\begin{array}{l}\text { Critical examining and } \\
\text { questioning of diversity } \\
\text { and multiculturalism }\end{array}$ & General & 27 & $\begin{array}{l}\text { Emotional Insights and } \\
\text { Personal Realization } \\
\text { over time: Gradual }\end{array}$ \\
\hline $\begin{array}{l}\text { Understanding and } \\
\text { identifying multiple } \\
\text { strands of diversity in } \\
\text { own personal life }\end{array}$ & General & 25 & $\begin{array}{l}\text { paradigm/worldview } \\
\text { shift and orientation to } \\
\text { practice }\end{array}$ \\
\hline $\begin{array}{l}\text { Bearing witness to } \\
\text { others hardships }\end{array}$ & General & 22 & \\
\hline $\begin{array}{l}\text { Early Exposure to Role } \\
\text { Models }\end{array}$ & General & 20 & \\
\hline Place Identity & Frequent & 16 & \\
\hline $\begin{array}{l}\text { Religious/spiritual } \\
\text { context }\end{array}$ & Frequent & 13 & \\
\hline $\begin{array}{l}\text { Undergoing personal } \\
\text { hardships }\end{array}$ & Frequent & 19 & \\
\hline \multicolumn{4}{|c|}{ Category: Perception of Key Learning Experiences } \\
\hline Domain & Representativeness & Number of cases & Overarching Theme \\
\hline $\begin{array}{l}\text { Formal Learning: } \\
\text { Practice based learning } \\
\text { through workplace }\end{array}$ & General & 25 & \\
\hline $\begin{array}{l}\text { Informal Learning: } \\
\text { Personal life events as }\end{array}$ & General & 26 & \\
\hline
\end{tabular}




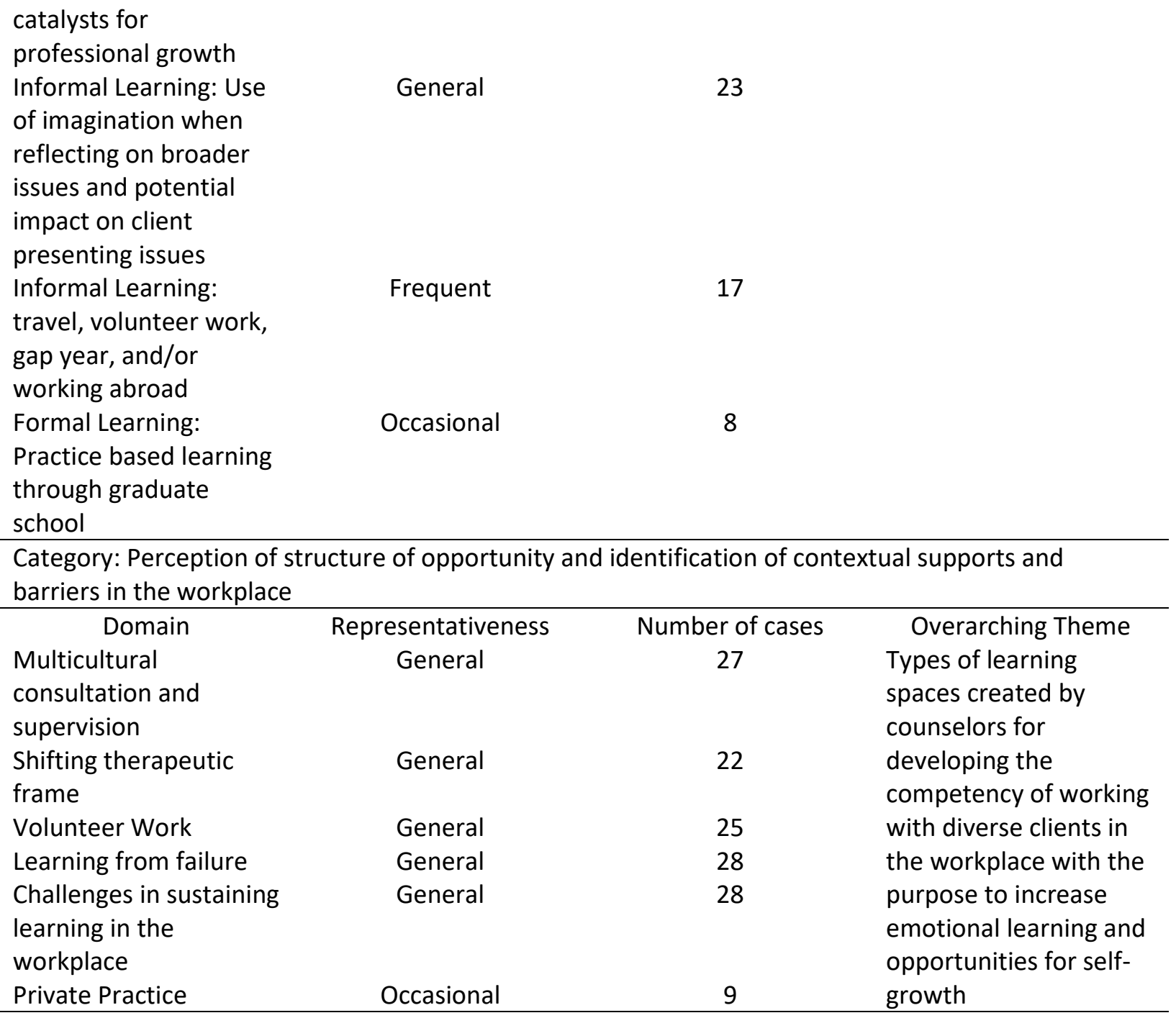

Category: Perception of choice goals and actions that contribute to professional resilience when working with diverse clients

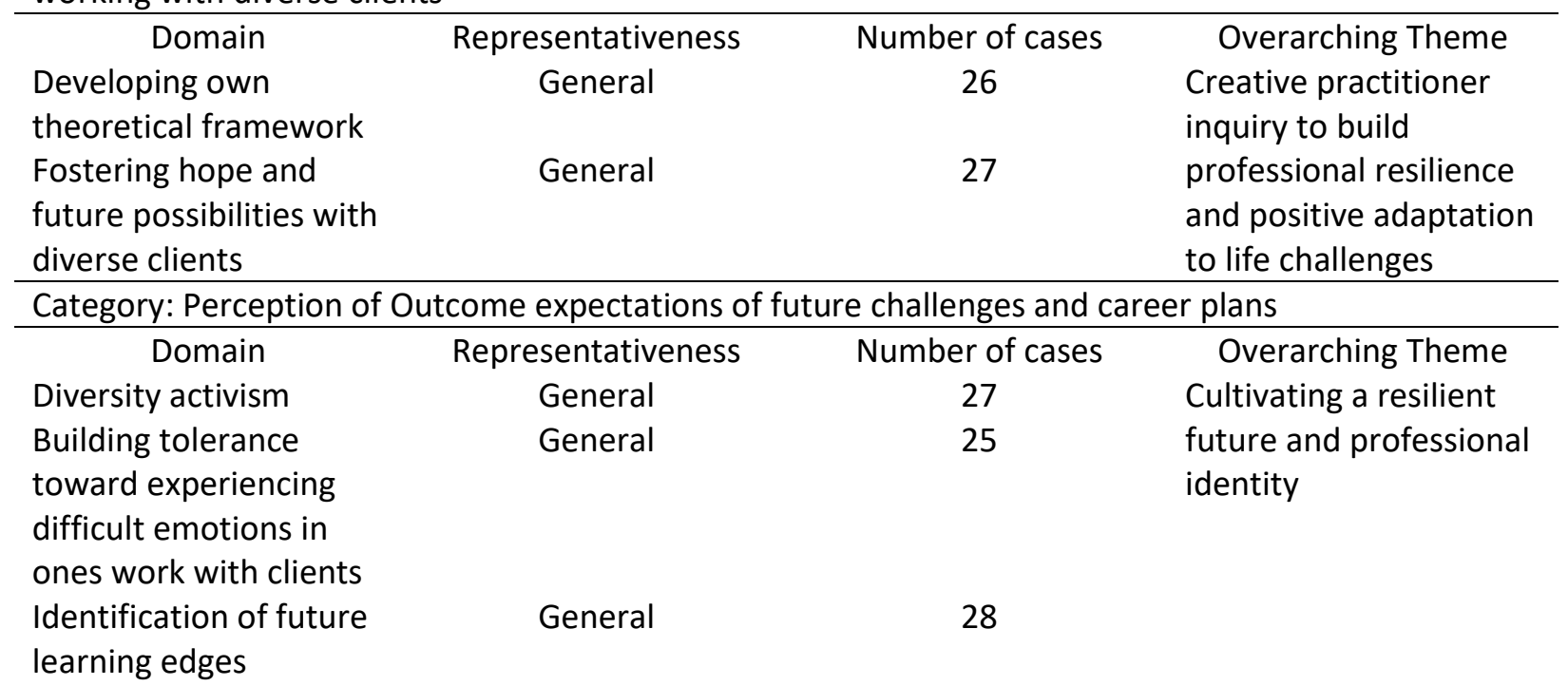


Mani

Further Graduate

Occasional

9

Education 


\section{References}

Abreu, J. M., Chung, R. H., \& Atkinson, D. T. (2000). Multicultural training: past, present, and future directions. The Counseling Psychologist, 28, 641-656. doi: $10.1177 / 0011000000285003$

Aldiabat, K., \& Le Navenec, C. (2018). Data Saturation: The Mysterious Step in Grounded Theory Methodology. The Qualitative Report, 23(1), 245-261. Retrieved from http://nsuworks.nova.edu/tqr/vol23/iss1/18

American Psychological Association. (2017). Multicultural guidelines. An ecological approach to context, identity, and intersectionality. Retrieved from http://www.apa.org.uml.idm.oclc.org/about/policy/multicultural-guidelines.aspx

Arredondo, P., \& Toporek, R. (2004). Multicultural counseling competencies=ethical practice. Journal of Mental Health Counseling, 26(1), 44-55. Retrieved from http://search.proquest.com/docview/198702140/

Arthur, N. (2018). Counselling in cultural contexts : identities and social justice . Cham, Switzerland: Springer.

Arthur, N., \& Collins, S. (2009). Culture-infused counselling supervision. In N. Pelling, J. Barletta, \& P. Armstrong (Eds.), The practice of clinical supervision (pp. 267-295). Bowen Hills: Australia Academic Press.

Arthur, N., \& Collins, S. (2014). Counsellors, Counselling, and Social Justice: The Professional Is Political. Canadian Journal of Counselling and Psychotherapy, 48(3), 171-185. doi: 1555665611

Arthur, N., \& Collins, S. (2015a). Multicultural counselling in Canada: Education, supervision, and research. In A. Sinacore \& F. Ginsberg (Eds.), Canadian counselling and psychology in the 21st century (pp. 42-67). Montreal, QC: McGill-Queen's University Press

Bandura, A. (1986). Social foundations of thought and action : A social cognitive theory / Albert Bandura. (Prentice-Hall series in social learning theory). Englewood Cliffs, N.J.: PrenticeHall.

Barden, S. M., \& Greene, J. H. (2015). An investigation of multicultural counselling competence and multicultural counselling self-efficacy for counsellors-in-training. International Journal for the Advancement of Counselling, 37(1), 41-53. doi: 10.1007/s10447-014-9224-1.

Brown, S., \& Lent, R. (2017). Social Cognitive Career Theory in a Diverse World: Closing Thoughts. Journal of Career Assessment, 25(1), 173-180. doi: 10.1177/1069072716660061

Casas, J. M., Park, Y. S., \& Cho, B. (2010). The multicultural and internationalization counselling psychology movement: When all is said and done, it's all multicultural, isn't it? In J. G. Ponterotto, J. M. Casas, L. A. Suzuki, \& C. M. Alexander (Eds.), Handbook of multicultural counselling (3rd ed., pp. 189-200). Thousand Oaks: Sage.

Clark, A. (2010). Empathy: An Integral Model in the Counselling Process. Journal of Counselling and Development : JCD, 88(3), 348-356. doi: 10.1002/j.1556-6678.2010.tb00032.x

Collins, S. (2010). Culture-infused counselling: A fresh look at a classic framework of multicultural counselling competencies. Counselling Psychology Quarterly, 23(2), 203-216. doi: 10.1080/09515071003798204 
Collins, S., \& Arthur, N. (2010). Culture-infused counselling / editors: Nancy Arthur and Sandra Collins. (2nd ed.). Calgary: Counselling Concepts.

Collins, S., \& Arthur, N. (2010). Culture-infused counselling: A model for developing multicultural competence. Counselling Psychology Quarterly, 23(2), 217-233. doi: 10.1080/09515071003798212

Collins, S., Arthur, N., Brown, C., Kennedy, B., \& Roberts, M. C. (2015). Student Perspectives: Graduate Education Facilitation of Multicultural Counselling and Social Justice Competency. Training and Education in Professional Psychology, 9(2), 153-160. doi: 10.1037/tep0000070

Collins, S., Arthur, N., \& Wong-Wylie, G. (2010). Enhancing Reflective Practice in Multicultural Counselling Through Cultural Auditing. Journal of Counselling \& Development, 88(3), 340347. doi: 10.1002/j.1556-6678.2010.tb00031.x

Chopra, T. (2013). All supervision is multicultural: A review of literature on the need for multicultural supervision in counselling. Psychological Studies, 58(3), 335-338. doi: 10.1007/s12646-013-0206-X.

Day-Vines, N., Booker, B., Steen, S., \& Arnold, K. (2018). Getting Comfortable with Discomfort: Preparing Counsellor Trainees to Broach Racial, Ethnic, and Cultural Factors with Clients during Counselling. International Journal for the Advancement of Counselling, 40(2), 89-104. doi: 10.1007/s10447-017-9308-9

Drapela, V. J. (1990). The value of theories of counselling practitioners. International Journal for the Advancement of Counselling, 13, 19-26.

Duncan, G., Kirkendall, N., \& Citro, C. (Eds.) (2014). The National Children's Study 2014: An Assessment. Washington, D.C. : National Academies Press.

Frank, J. (1972). Common Features of Psychotherapy. Australian and New Zealand Journal of Psychiatry, 6(1), 34-40.

Graneheim, U. H., \& Lundman, B. (2004). Qualitative content analysis in nursing research: Concepts, procedures and measures to achieve trustworthiness. Nurse Education Today, 24(2), 105-112. doi: 10.1016/j.nedt.2003.10.001

Hall, K., Barden, S., \& Conley, A. (2014). A relational-cultural framework: Emphasizing relational dynamics and multicultural skill development. The Professional Counsellor, 4(1), 71-83. doi: $10.15241 / \mathrm{kgh} .4 .1 .71$

Helms, J. E., \& Richardson, T. Q. (1997). How "multiculturalism" obscures race and culture as differential aspects of counselling competency. In D. B. Pope-Davis \& H.L.K. Coleman (Eds.), Multicultural counselling competencies: Assessment, education and training, \& supervision (pp. 60-79). Thousand Oaks, CA: Sage.

Hennink, M., Kaiser, B., \& Marconi, V. (2017). Code Saturation Versus Meaning Saturation: How Many Interviews Are Enough? Qualitative Health Research, 27(4), 591-608. doi: $10.1177 / 1049732316665344$

Hill, N. R. (2003). Promoting and celebrating multicultural competence in counsellor trainees. Counsellor Education and Supervision, 43(1), 39-51. doi: 10.1002/j.15566978.2003.tb01828.x.

Hook, J. N., Davis D., Owen J., \& DeBlaere, C. (2017). Cultural humility: A guide to engaging diverse identities in therapy. Washington, DC: American Psychological Association. 
Hsieh, H., \& Shannon, S. (2005). Three Approaches to Qualitative Content Analysis. Qualitative Health Research, 15(9), 1277-1288. doi: 10.1177/1049732305276687

Jones, J.M., Kawena, B. K., Nakagawa, Y., Cevasco, M., \& Sit, J. (2016) Multicultural Counselling Competence Training: Adding Value With Multicultural Consultation, Journal of Educational and Psychological Consultation, 26:3, 241-265, DOI: 10.1080/10474412.2015.1012671

Knapik, M., \& Miloti, T. (2006). Conceptualizations of Competence and Culture: Taking Up the Postmodern Interest in Social Interaction. International Journal for the Advancement of Counselling, 28(4), 375-387. doi: 10.1007/s10447-006-9024-3

Knox, R. (2013). Relational depth: New perspectives and developments.. Basingstoke: Palgrave Macmillan.

Køster, A. (2017). Personal History, Beyond Narrative: An Embodied Perspective. Journal of Phenomenological Psychology, 48(2), 163-187. doi:10.1163/15691624-12341327

Kottler, J., \& Balkin, R. (2016). Relationships in counselling and the counsellor's life. Washington, D.C.: American Counselling Association.

Kramer, C. H. (2000). Therapeutic mastery: Becoming a more creative and effective psychotherapist. Phoenix, AZ: Zeig, Tucker.

Lee, C. C. (2013). Multicultural issues in counselling: New approaches to diversity. Alexandria: American Counselling Association.

Lent, R. W. (2013). Career-life preparedness: Revisiting career planning and adjustment in the new workplace. The Career Development Quarterly, 61, 2-14. doi:10.1002/j.21610045.2013.00031.x

Lent, R. W. (2013a). Social Cognitive model of career self-management: Toward a unifying view of adaptive career behavior across the life span. Journal of Counselling Psychology, 60(4), 557568. doi: $10.1037 / \mathrm{a} 0033446$

Lent, R. W. (2016). Self-Efficacy in a Relational World: Social Cognitive Mechanisms of Adaptation and Development. The Counselling Psychologist, 44(4), 573-594. doi: 10.1177/0011000016638742

Lent, R. W., Brown, S. D., \& Hackett, G. (2000). Contextual Supports and Barriers to Career Choice: A Social Cognitive Analysis. Journal of Counselling Psychology, 47(1), 36-49. doi: 10.1037//0022-0167.47.1.36

Lent, R.W., Ezeofor, I., Morrison, M. A., Penn, L.T., \& Ireland, G.W. (2016). Applying the social cognitive model of career self-management to career exploration and decisionmaking. Journal of Vocational Behavior, 93, 47-57. doi: 10.1016/j.jvb.2015.12.007

Manese, J. E., Wu, J. T., \& Nepomuceno, C. A. (2001). The Effect of Training on Multicultural Counselling Competencies: An Exploratory Study over a Ten-Year Period. Journal of Multicultural Counselling and Development, 29(1), 31-40. doi: 10.1002/j.21611912.2001.tb00501.x

May, V. M. (2015). Pursuing intersectionality, unsettling dominant imaginaries. New York: Routledge, Taylor \& Francis Group.

Miller, M., Sendrowitz, K., \& Mallinckrodt, B. (2011). Counselling Psychology Trainees' Social Justice Interest and Commitment. Journal of Counselling Psychology, 58(2), 159169. doi: $10.1037 / \mathrm{a} 0022663$ 
Mosher, D., Hook, J., Captari, L., Davis, D., DeBlaere, C., Owen, J., \& Zimmerman, J. (2017). Cultural Humility: A Therapeutic Framework for Engaging Diverse Clients. Practice Innovations, 2(4), 221-233. doi: 10.1037/pri0000055

Neville, H. (2015). Social Justice Mentoring: Supporting the Development of Future Leaders for Struggle, Resistance, and Transformation. The Counselling Psychologist, 43(1), 157-169. doi: 10.1177/0011000014564252

Norcross, J., \& Wampold, B. (2011). What works for whom: Tailoring psychotherapy to the person. Journal of Clinical Psychology, 67(2), 127-12732. doi: 10.1002/jclp.20764

Palmer, A., \& Parish, J. (2008). Social Justice and Counselling Psychology: Situating the Role of Graduate Student Research, Education, and Training. Canadian Journal of Counselling, 42(4), 278-292. Retrieved from http://uml.idm.oclc.org/login?url=https://search-proquestcom.uml.idm.oclc.org/docview/195821168?accountid=14569

Pedersen, P. (2001). Multiculturalism and the Paradigm Shift in Counselling: Controversies and Alternative Futures. Canadian Journal of Counselling, 35(1), 15-25.

Peters, H. C. (2017). Multicultural Complexity: An Intersectional Lens for Clinical Supervision. International Journal for the Advancement of Counselling, 39(2), 176-187. doi: 10.1007/s10447-017-9290-2

Ratts, M. J., \& Pedersen, P. (2014). Counselling for multiculturalism and social justice: Integration, theory, and application (Fourth ed.). Alexandria: American Counselling Association.

Ratts, M. J., Singh, A. A., Nassar-McMillan, S., Butler, S. K., \& McCullough, J. R. (2016). Multicultural and social justice counselling competencies: Guidelines for the counselling profession. Journal of Multicultural Counselling and Development, 44(1), 28-48. doi: 10.1002/jmcd.12035.

Ridley, C., Baker, D., \& Hill, C. (2001). Critical Issues Concerning Cultural Competence. The Counselling Psychologist, 29(6), 822-832. doi: 10.1177/0011000001296003

Sandelowski, M. (2000). Focus on research methods: Whatever happened to qualitative description? Research in Nursing and Health, 23(4), 334-340. doi: 10.1002/1098-240X

Schreier, M. (2014). Qualitative content analysis. In Flick, U. The SAGE handbook of qualitative data analysis (pp. 170-183). London: SAGE Publications Ltd. doi: 10.4135/9781446282243

Shepherd, D., Patzelt, H., \& Wolfe, M. (2011). Moving forward from project failure negative emotions, affective commitment, and learning from the experience. Academy of Management Journal : AMJ, 54(6), 1229-1259. doi: 10.5465.amj.2010.0102

Speight, S. L., \& Vera, E. M. (2008). Social justice and counselling psychology: A challenge to the specialty. In S. D. Brown \& R. Lent (Eds.), The handbook of counselling psychology (4th ed., pp. 54-67). Hoboken, NJ: Wiley.

Sterner, W. R. (2012). Integrating Existentialism and Super's Life-Span, Life-Space Approach. Career Development Quarterly, 60(2), 152-162. doi:10.1002/j.21610045.2012.00013.x

Sue, D. W. (2001). Multidimensional Facets of Cultural Competence. The Counselling Psychologist, 29(6), 790-821. doi: 10.1177/0011000001296002

Sue, D. W., \& Sue, D. (2013). Counselling the culturally diverse: Theory and practice (6th ed.). Hoboken: Wiley. 
Sue, D. W., Parham, T. A., \& Bonilla-Santiago, G. (1998). The changing face of work in the United States: Implications for individual, institutional, and societal survival. Cultural Diversity and Mental Health, 4, 153-164.

Super, D. E. (1990). A life-span, life-space approach to career development. In D. Brown, L. Brooks, \& Associates (Eds.), Career choice and development: Applying contemporary theories to practice (2nd ed., pp. 197-261). San Francisco, CA : Jossey-Bass.

Swartz, M. R., Limberg, D., \& Gold, J. (2018). How Exemplar Counsellor Advocates Develop Social Justice Interest: A Qualitative Investigation. Counsellor Education and Supervision, 57(1), 18-33. doi: 10.1002/ceas.12091

Trede, F., \& McEwen C. (2012) Developing a Critical Professional Identity. In J. Higgs, R. Barnett, S. Billett, M. Hutchings, \& F. Trede (Eds.), Practice-Based Education. Practice, Education, Work and Society (pp. 27-40). Rotterdam: Sense Publishers.

Trimble, J. (2010). Bear spends time in our dreams now: Magical thinking and cultural empathy in multicultural counselling theory and practice. Counselling Psychology Quarterly, 23(3), 241-253. doi: 10.1080/09515070.2010.505735

Vera, E. M., \& Speight, S. L. (2003). Multicultural competence, social justice, and counselling psychology: Expanding our roles. Counselling Psychologist, 31, 253-272. doi: 10.1177/0011000003031003001

Wheeldon, J., \& Faubert, J. (2009). Framing Experience: Concept Maps, Mind Maps, and Data Collection in Qualitative Research. International Journal of Qualitative Methods, 8(3), 6883. doi: 10.1177/160940690900800307

Wiggins, S., Elliott, R., \& Cooper, M. (2012). The prevalence and characteristics of relational depth events in psychotherapy. Psychotherapy Research, 22(2), 139-158. doi: 10.1080/10503307.2011.629635

Wong-Wylie, G. (2006). Narratives of developing counsellors' preferred theories of counselling storied through text, metaphor, and photographic images. (Report). The Qualitative Report, 11(2), 262-301. Retrieved from http://nsuworks.nova.edu/tqr/vol11/iss2/4

Yin, R. (2009). Case study research: Design and methods / Robert K. Yin. (4th ed., Applied \ social research methods series; 5). Los Angeles, CA: SAGE. 